\title{
Methods of Studying the Semantic Function of Trademarks in the Industrial, Commercial and Advertising
}

\author{
Stadulskaya N.A ${ }^{1} \&$ Antipova L.A ${ }^{2}$ \\ ${ }^{1}$ Pyatigorsk Medical \& Pharmaceutical Institute \\ ${ }^{2}$ Candidate of Pedagogical Sciences, assistant professor, Pyatigorsk Medical and Pharmaceutical Institute - a branch of \\ the Federal State Budget Institution of Higher Education, Russia
}

Correspondence: Stadulskaya N.A, Pyatigorsk Medical \& Pharmaceutical Institute, Russia. E-mail: info@rosminzdrav.ru

Received: July 17, 2019

Accepted: September 10, 2019

Online Published: October 28, 2019

doi:10.5430/ijhe.v8n7p1

URL: https://doi.org/10.5430/ijhe.v8n7p1

\begin{abstract}
Of the aim of this investigation is to show the methods of studying the trademarks development to better understand their role in modern economy and advertising. Along with the methods, we have tried to postulate that the concept "property" accelerate their wide-spreading and necessity. It was established that the creators (brand designers) use some cognitive techniques to make a new trade-name. Often some semantic methods help them to from a new name and in the article we tried to illuminate this linguistic aspect. Taking into consideration that all of our research is made into the semiotics field of science, we, of course, drew attention to the pragmatic aspect of the investigated linguistic material. We concluded that, all trademarks in certain teaching methods, effort at the implementation of the commercial intentions. The present article deals with the educational approaches aimed at the development of a positive evaluation in the perception of this or that trademark; phonosemantic strategies, implemented in the process of brand naming, are shown. According to the results we are going to continue our investigation in the field of semiotics, in other words we want to study verbal, non-verbal and heterogenous brands and mechanism and models of the methods.
\end{abstract}

Keywords: semantics, phonosemantics, trademark, brand naming

\section{Introduction}

It is common knowledge that functions express certain dependence of one variable from another. This allows us to understand certain language mechanisms of some vocabulary phenomena determining its essence. In addition, the knowledge in this field could reveal natural connections of its units.

The tradition of marking objects, currently carried out with the help of signs of different physical nature, designed for different sensory channels of perception, has a long history in English culture, associated with the formation of the concept of property, objectified in acts of appropriation or alienation of property. Marking of ownership of goods and services is an integral part of modern production and economic activities of advertising, commercial and communication. The undoubted social and cultural significance of trademarks makes their study one of the most important areas of modern socially and culturally oriented linguistics. Trademarks have repeatedly attracted the attention of researchers, but to date, no attempts have been made to consider ownership signs in terms of the relationship between the vocabulary of language and non-linguistic reality and the creation of a Central concept of a trademark and a brand as a sign phenomenon of language and culture, which all this concept are related to each other taking their same root in culture and language.

The object of this study are the trademarks of the United States and the United States, interpreted as an artificial polycode system, which includes means of objectification of the concept of ownership, the right to which is registered and protected by law. The choice of English and American trademarks as an object of research is of particular relevance, since the tradition of their creation and use, which is entrenched in Western European culture, has led to the spread of the practice of labeling of goods and services in the world and determined the formation of the concepts of trademark and brand - universal concepts of modern human culture. 
The history and Genesis of the trademark and brand are inextricably linked to the development of private property, which led to the emergence of labeling of property as goods intended for trade. The custom of marking items of property and goods existed in ancient times: artisans of ancient Rome, who produced pottery, put their brands on them, allowing buyers who appreciated the quality of the products of any craftsman, when re-buying, to turn to these masters.

The basis of modern trademark legislation in different countries was the legislation on the right of ownership. So, in England in 1300 a law was passed, forbidding the sale of gold and silver jewelry without a special mark guaranteeing the quality of the product. This mark was called the "Leopard's head". The decree of king Edward I prescribed that every jeweler should have his own brand. The presence of the mark on the product indicated that the quality of the goods by the artisan meets the requirements. In those days, the population of the country was not literate, so, as a rule, the stigma of individual artisans were conventional figurative elements - symbols, but not names or initials. In contrast, the mark of the Guild of the Corporation of its trademark containing the names.

In Germany, regular marking of pottery was introduced in 1723, the Meissen factory has announced a brand of their products, the letters "KRM" and the picture of the crossed swords is the element of the coat of arms of Saxony. Other factories also began to use signs including heraldic symbols for marking their products. In France, since 1766, porcelain manufacturers had to register their trademarks at the police station. When in Western Europe there is national trade Guild, and the stigma began to be entered in special registers. This period can be considered as the beginning of the creation of centralized registration of trademarks, the prototype of modern state registers. By the mid-20th century, trademark registration had become mandatory; today, registered trademarks are protected by law. These data on the history and evolution of property signs confirm the position on the determining influence of socio-cultural and economic factors on the formation of the concept of property and the variety of means and methods of its objectification in the culture Of the United States and the United States.

In the history of the origin and evolution of signs, in different countries of brand-driving and protecting the right of ownership of goods and services, there is an obvious analogy, which is confirmed by historical, archaeological and anthropological studies. In the society of different ethnic groups and nationalities, the development of industrial and commercial relations is associated with the emergence of the concept of property. The prototypes of modern signs of ownership were rock paintings, primitive signs, notches, evolved over time into brands, stamps, signatures, brands and trademarks. The very concept of property begins to form at the dawn of economic relations in human society. In primitive society, one of the determining conditions for human survival was the availability of tools and housing, so the right of ownership, expressed by the act of appropriation or alienation, became the primary basis for the distinction between "one's" and "another's".

Modern trademarks, diverse in semiotic characteristics, both verbal and non-verbal, guarantee the authenticity of the objects and services marked by them and act as a universal and multifunctional means of inter-linguistic and intercultural communication.

Continuous replenishment of communication means with new formations - units that nominate or otherwise mean objects, processes, phenomena and concepts that characterize and increasingly complicate the picture of the world of modern people, causes an unrelenting interest of researchers around the world. These units include the trademark and brand as a symbol of high quality goods/products/services. They are integral elements of cultural and linguistic consciousness of modern people; without their study, it is impossible to raise and solve the question of the impact of society on the formation of the picture of the world and the speaker's personality. Not a case but, therefore, that the study of problems connected with creation and functioning of services for trademarks, today, are not only lawyers, marketers, specialists in brandraising and advertisers, but also psychologists, experts in the field of communication theory and linguists. However, to date, the phenomenon of the trademark, as well as the directly related phenomenon of the brand, scientifically based theoretical interpretation and objective system description have not been received.

\section{Materials \& Methods}

The past few years investigations have seen the development and entrenchment of a research methodology within the field of semantics that comprises any two or more of the following phases: identification of a semantic problem analysis of the problem within the framework of one or more linguistic frameworks (hypotheses, methods, data); a semantic perspective on the problem, i.e. an analysis of current and past approaches (assumptions, methods, procedures, techniques) to the problem within semantics itself.

The corpus consists of 500 trade names collected by continuous selection from the company's online shops, catalogues, ads. 
First of all we selected them into different groups according to their semantic meanings and then we learnt their pragmatics. Then, on the basis of the descriptive method we carefully analyzed all the examples of trade names, dividing them according to their components and functions.

We tried to find and to describe the obvious and latent meanings of word trade - marks, trade names that is to show the hidden characteristics of the advertised product. Often to achieve the aim we used the principles of etymological analysis.

We also used etymological analysis, comprising the elucidation of the pre-existing morphological structure of the word, its past word-formation relationships, the definition of the source and time of the word, the establishment of the method of its formation from the corresponding producing basis. By the way, etymology helps to shows the hidden senses of trade names best of all, as the brand-owners prefer to use such extraordinary method to give a name to a new product to sound more authoritatively.

In addition to the above described methodological framework, we used component analysis of product names. We defined component analysis of the lexical meaning of the word as a method to identify the words components (semes) meaning, which make up their content. Component analysis is based on data from dictionaries. To fulfil component analysis we used two steps: (1) method of step identification - where the main objective is the identification finding, combining the similar meaning of the word. The identification in that case continues until there is a situation of mutual determination or until there is a situation of definition through descriptive language (both means that further clarification is not possible). And (2) definition analysis: dictionary definition analysis and specific semantic features identification that distinguish a given word from words close to it in meaning

The order of analysis can be described as following:

1. Determine the meaning of the word in the thesaurus.

2. Refine the identified value components by applying a step-by-step identification procedure and a definition analysis.

3. Organize the received data. Identify the components (semes) of the lexical meaning of the analyzed word and arrange them in a hierarchical order according to categorical-grammatical features, lexical and grammatical features, categorization, differentiation and connotative components (emotional-evaluative, functional-stylistic etc) detection.

\section{Results}

Semantic function of trademarks in the industrial, commercial and advertising discourses primarily includes sub-functions comparison expressed in comparison of the property and quality of the so-called trademark with the product itself. The following examples illustrate the comparison with:

lifetime duration - dura (durable), perma (permanent): Duracell, DuraShocks, DuraLong, Permawear, PermaLight;

speed of action - insta (instant), long (long), kweek (quick); QuickStep, Kweeky, DuraLong, the quicktionary, InstaLux;

product quality - econom (economical), intell (intelligent), bio - biological), sol (solid): INSTAPUMP, EcoMatic, BioBalance, Intellimouse, Intellowasher, I-Pad, Dynarec, I-sol, Eco-Dry;

product size - Giant (plane), Green Giant (Green Giant - peas);

substance which is a part of the product - Double Mint (double mint), Inamel (enamel - enamelled iron sheets);

person or subject - Tourist (camp gas stove), Tough Stuff ('durable fabric' - thread for fabrics);

place where the product can be used - Port (port radio station), Jazzmaster ('master of jazz' - electric guitar);

product quality - Ex-1-ent, Purr-fect, Classic (model - oil filter), Select ('selected' - salt for recharging the water softeners), Just wonderful - paint;

subject operation - Kantleke (can't leak - 'can't leak') - pipes; Kant-twist (can't twist - 'can't twist') step-ladder (examples from (Braun, O. \& Wicklund, R., 1989));

subject function - Solve - cleanser, Digz-all - ditch digger, Fitz-m-all - (fit for all of them) - hanger, Stop-kof (stop cough) - cough remedy;

place of manufacture - Florida (bathroom equipment), Illinois (cutting tools);

manufacturing company - PPP - Pontiac Plastic Products;

subject of the same area - Simphony (radio gramophone), Gaiety (electric phonograph); 
Along with the comparison sub-function, it is useful to distinguish associative sub-function. In this case, the choice of the first basics for trademarks can be based on the suggestive, as well as emotional and expressive functions of the lexical units. Suggestive basics do not contain specific information about the product, but allow the buyer to judge the merits of the product by his own (ALL-GUARD - watch). Some of the basics of names not even draw attention to the product, but are intended only to surprise receptor to some extent, for example, GOSTMASTER - primer-detonator, where the basic is 'the ghost'. There technique, known as 'deceived expectations' in stylistics, is used. In many cases, basics of trademarks could expressly or associative indicate such valuable consumer quality of products as: long lifetime duration (dura $\rightarrow$ durable; perm $\rightarrow$ permanent), performance (speed-, time-, instant-, pace-, rate-, jet-, rocket-), efficiency (econo-), reliability (sure), durability (tough-), portability (mini-, handy), ease of use (easy-, simply-, ready), facilitation of labor as a result of the fact that the mechanism operates using electrical energy (electro-, dyn-, power-, volt-, charge-, plug-), superiority over other products (super-, select-, ultra-, top-, star-, astr-), good product quality (perfect-, swell-, gold-, quali-, magic-). For example: Durex, Electrolux, Golden Eye, SpeedWay, SuperDone, etc.

\section{Discussion}

Thus, successful implementation of industrial, commercial and advertising activity involves development of a positive image of the participants themselves, their products proposed and services rendered. Achievement of this goal in contemporary brand naming includes the development of trademarks having potential for formation of positive associations.

For the purposes of attractiveness of this or that trademark, advertisers often pay attention to the concept of sonority which makes up phonosemantic sub-function.

Names of such industrial materials, such as VELCRO, TEFLON, TYVEK, TREX, etc. represent a model of implementation of the brand naming professional knowledge. These names appeal to the materials, which surround us in everyday life, and which are 'the material of our lives'. They can be fabrics, building materials, coatings, various substances, etc. Some of the names, such as NYLON and RAYON (examples from (Cann, Ronnie, 1964)), were invented as generic names (i.e. as the general material designation, not a trademark), while others, for example, CELLOPHANE and LINOLEUM (examples from (Cann, Ronnie, 1964)), initially were the trademarks and only then become generic names. But pragmatically successfully developed product name is the basis for development of other distinctive brands. Trademark, followed by the generic name, is an example of the most effective names of products and services, which lost their relevance due to the uncontrolled use or improper legal protection.

Many of the pragmatically effective trademarks have one thing in common: semantically, they embody the product essence, as their constituent morphemes and individual patterns reflect the product characteristics, appearance and function, although it is not always obvious. Such names allow product 'to speak for itself'. The following brief analysis of the famous material brands shows the implementation of phonosemantic concept in the brand naming.

To begin with, let's consider VELCRO, the name of which includes VEL, which means a flexible material, such as in VELOUR, VELVET, and CR - the sound connoting the functions of adhesion and cohesion. It can be seen in the examples, such as CROCHET, CRIMP or CRUNCH, or on the 'sister sound' of GR in the examples, such as GRIP, Graf or GRASP. The last element of this verbal construction is an ending of $\mathrm{O}$, which expresses belonging to the masculine gender in many languages of the Romance group, which can be compared with the functionality of the product, unlike the female ending of A, for example, VELCRA, which is a trademark of fiber like lycra (LYCRA). In general, CRO is associated with CROCHET (literary, hook; crochet; to needlepoint); this brand denotes 'the hook-and-loop fastener' (velcro). Such a descriptive name is very 'strong' and dominates within the frameworks of the modern market technology.

Next name under study is TEFLON. This name is easy to understand by decrypting the chemical name polyTEtraFLuOroethyleNe, which means 'strong' or 'tough' (Tough = TEF), flat material (LON), as, for example, in the trademarks of NYLON, ORLON. Compare: TUFCOAT or TUFLON would be obvious and 'weaker'.

TYVEK is a material used in packing, where TY is connoting with TYING in connection with the fact that it is used for wrapping and tightening of different objects. The middle $\mathrm{V}$ means flexibility, the ending $\mathrm{K}$ reflects force. Thus, trademark of TYVON obviously refers to the functions of coverage of the present flexible material for the construction facility.

The simplest technology for the trademark development is the processing or adaptation of the generic name for this product. Such technology could generate small-associative names, which, however, could be effective. TWEED (generic name) originates from the Scottish word TWEEL, which means twill - 1) twill fabric, serge; 2) to bind diagonally, which means twisting, fabric tangle. Ending of D perfectly explains density and endurance of woolen 
fabric and its relatively raw surface. Compare BONDO. Only one extra letter O separates this trademark of the well-known reality of BOND; this key function is reflected in such names as TIMEX, SPEEDO, JELL-O. Compare also pragmatonym SPANDEX, being an anagram from EXPANDS, which means the material elasticity.

In order to create a highly associative advertising name, manufacturer or advertiser should possess not only background knowledge, but also knowledge of semantics, pragmatics, phonosemantics, morphology, etc.

For example, suffixes play a crucial role in the expression of the material essence. Certain suffixes and morpheme endings could show product characteristic. For example, suffix of ITE means solid, sometimes hard material, as in pragmatonym LUCITE (acrylic glass) and LEXITE (compound which replaces wood). Adding L and ITE using LITE as a suffix, as, for example, in KENLITE (lightweight structural concrete) and THERMOLITE (very light fiber), the advertiser could invest sense of substance lightness and could probably highlight the environmental friendliness of the product. EX often means (from 'flexible') flexible; bendable; soft, resilient material, as, for example, in pragmatonyms SPANDEX, OREX (light resilient fabric); adding T to get TEX is obviously connoting with textiles, for example, GORE-TEX, ANSO-TEX. TEC / TEK / TECH, on the other hand, clearly show the high-tech material, as in pragmatonyms POLARTEC, RHINOTEK (high-tech abrasion-resistant fabric). ON, for example, in the product names of DACRON and RAYON, especially when adding L (NYLON, ORLON), denotes soft and smooth material. COR(E) denotes solid material, which is used for the manufacture of durable, strong subject matter, for example, GRIDCORE (material made of compressed cellulose, which replaces wood and other solid materials) and DORCOR (construction non-metallic composite panels). Very often, ending of UM indicates solid material, probably imitating solid elements, such as ALUMINIUM, CALCIUM, LITHIUM. Examples include LINOLEUM, originally made of linseed oil (LIN (linseed) and OLE (oil)), and BORIUM (hard alloy metals used for boring and drilling).

In the same way, different prefixes may have a certain connotation, for example, CEL(L) denotes cellulose (CELLOPHANE); THERM denotes heat, for example, THERMORE; POLAR connotes with 'cold', for example, POLARGUARD; LIN indicates linseed oil (LINOLEUM).

We have studied a number of letters and recurrence of their use in the process of brand material nomination. In the course of the study, we asked ourselves another question: whether other graphic symbols could, for example, play a pragmatic role in the process of nomination of the products and goods of other regions (not material), for example, PRODUCT 19, CHANEL No 5, WD-40, 4711, MOTEL 6, 37 SIGNALS? The answer is negative, while the purpose of the material nomination is often limited to the designations of its advantages; use of the numeral as a prefix, suffix or a connecting element reduces the universality of the name. Of course, there is a small number of pragmatonyms for materials, which are comprised only by numbers, for example, eau de cologne 4711 or jeans 501. It is much more efficient to use the name PLEXIGLAS instead of PLEXIGLAS 17. Perhaps, construction of WD-40 (generator trademark; figure 40 denotes total number of attempts to develop generator of the 'extrusion' system) has a right to exist, but it has not a character of universality, as, for example, the names of VELCRO, TEFLON, SPANDEX. However, it should be noted the practical use of numerals in high-tech material grades, for example, in a pragmatonym WR 100X (waterproof high-quality fabric).

If the product becomes renowned worldwide, then there is a big probability of transition of the pragmatonym to the species name (Cellophane, Linoleum). Names of any of the materials most likely become species-specific names because of their novelty and uncertainty. Being semantically similar to their product, they become a part of the product designated. If the name is not 'bound' to the product, it will not be associated with similar products, for example, ECLIPSE (nylon fabric name), AUGUSTA (cotton fabric name), ENTRANT (sportswear name), KIWI (shoe polish name), APPLE (computer manufacturer name), SATURN (car manufacturer name). Thus, product names are given the secondary pragmatic approach - to designate the product or service not with direct, but indirect association. Such names may have the blend nature, for example, CORDURA (COR(D)+(D)URA - nylon fabric for handbags), THINSULATE (THIN+INSULATE - warm and light microfiber), SENSURA (SENS(E)+ENSUR(E) - high-tech, soft and strong fiber).

\section{Conclusion}

Throughout the twentieth and early twenty-first century, research in the area of naming are being carried out by linguists, cultural scientists, psychologists, sociologists. These studies occupy one of the most important places in the cognitive science that originated abroad in the 60s-70s of the twentieth century. Today you can quite objectively say that in the first decade of the XXI-th century, the Linguistic science finally established a new cognitive research paradigm and the corresponding conceptual scheme of analysis, a new model formulation and solution of research problems. One such task was the explanation of how to create new names and how different semantic entities function. 
The main postulates of cognitive linguistics, defining its main difference from structuralism, are considered to be the postulates of integrativity and anthropocentrism. Integrity involves the study of the functioning of the object, i.e. from the point of view of what processes lead to its formation and how it is used to solve specific communication problems. Anthropocentrism means that the focus of the researcher is a person with his ability to create and, in accordance with the communicative attitude and conditions of communication to use differentially signs and sign systems. In its semantic content, verbal and non-verbal signs reflect the interaction of psychological, cultural, sociological factors; therefore, they should be the subject of interdisciplinary research.

Contemporary society becomes development of the ideal brand concept, which means a set of representations of the native speaker on what should be the name of the advertised objects based on the grammatical form, semantics, sound appearance and outward appearance. Compliance of a specific trademark with the said concept is largely determined by its viability and possibility to be used in a great variety of communicative and pragmatic situations. The study found that one of the most important qualities of a trademark is its polyfunctionality. The trademark serves as the main communicative function, which is realized through cognitive, national-cultural and pragmatic functions. The cognitive function of a trademark is to express the result of human consciousness. The national and cultural function of a trademark is determined by its ability to store and transmit the specificity of the national consciousness and traditions of the carriers of this culture.

Next time we are going to analyze verbal, nonverbal and syncretic trademarks, which are an open heterogeneous artificial semiotic system of culture, the development of which is determined by the production and economic relations based on the determining role of property.

\section{References}

Andrews Mark, Gabriella Vigliocco \& David P. Vinson. (2009). Integrating experiential and distributional data to learn semantic representations. Psychological Review CXVI, 3.

Beverland, M. (2005). Crafting Brand Authenticity: The Case of LuxuryWines. Journal of Management Studies, 42(5), 1003-1029.

Braun, O. \& Wicklund, R. (1989). Psychological Antecedents of Conspicuous Consumption. Journal of Economics Psychology, 10(2), 161-187.

Cann, Ronnie. (1964). Formal semantics: studies in the science of meaning: Dover publications.

Chaffin, A. (1992). The Concept of a Semantic Relation. In: Lehrer \& Kittay (Eds.) 1992:253-288.Croft, W. 1993. The role of domains in the interpretation of metaphors and metonymies. Cognitive Linguistics, 4(4), 335-370

Collins Thesaurus [Text]. - Glasgow: Harper Collins Publishers, 1995-1070.

Dictionary of pub Names [Text]. - Wordsworth reference, 1994.

Etymology Dictionary [Electronic resource] / D. Harper. - HarperCollins Publishers 1995; 2002. - http://www. etymonline.com/

Gadzaov A.F. \& Dzerzhinskaya M.R. (2018). Mathematical methods of analysis of the periodic components of economic processes, Modern Economy Success, 1, 14-18.

Gadzhieva U.B. (2018). Socialization of Personality as a Factor in the Mental, Intellectual and Spiritual-Moral Development, International Journal of Medicine and Psychology, 1(2), 7-20.

Heine, K. (2010a). A Theory-based and Consumer-oriented Concept of Luxury Brands, In Pursuit of Luxury Conference, London.

Heine, K., Kübrich, K. \& Phan, M. (2010). The Definition of Luxury Products by their constitutive Characteristics, KAMS Fall Conference, Seoul.

Henderson, Geraldine R., Dawn Iacobucci \& Bobby J. Calder (2002). Using Network Analysis to Understand Brands, Advances in Consumer Research, 29, 397-405.

Jackendoff, Ray (1996). Conceptual semantics and cognitive linguistics, Cognitive Linguistics, 7(1), 93-129.

Koller, Veronika (2004a). Metaphor and Gender in Business Media Discourse, Basingstoke.

Melnikov V.M. (2002). Tovarnie znaki za rubezhom v kanun XXI veka. - M. Rospatent, 2002. 
Mendoza Velazco, D. J. \& Rivero Padrón, Y. (2019). Teaching Resource for the Teaching of Geometry: Circular Trigonometric Geoplane. International Electronic Journal of Mathematics Education, 14(1), 3-13. https://doi.org/10.12973/iejme/3936

Murray T.V. (1997). Problema "svoego" $i$ “chuzhogo" v context problem tsennosti chelovekal/ "Svoe” $i$ "chuzhoe” v culture narodov Evropeiskogo Severa - Pertozavodsk, 17-20.

Narkevich L.V. \& Narkevich E.A. (2018). Financial condition analysis in the crisis management system. Russian Economic Bulletin, 1(4), 10-24.

Selomo, M. R. \& Govender, K. K. (2016). Procurement and Supply Chain Management in Government Institutions: A Case Study of Select Departments in the Limpopo Province, South Africa.

Sergeeva M.G. \& Trubakova D.I. (2016). Teacher's Reflection Formation as Factor of Effectiveness Children's Social Intelligence Forming. Modern Scientist, 7, 62-64.

Tsahaeva A.A., Aminov U.K. \& Aminova D.K. (2017). Driving forces of the development of adaptive behavior of personality: methodological considerations. Modern Scientist, 8, 44-47.

URL: http://b-dictionary.globala.ru/brand, 2010.

URL: http://dictionary.reverso.net/english-definition/brand, 2009.

URL: http://www.thefreedictionary.com/brand, 2009.

Villalobos, J. V. (2018). Politics as a requirement. On the concept of Human Rights and the right to an autobiography as an ethical category. Opción, 34(85-2), 9-19.

Wierzbicka, Anna (1991). Cross-cultural Pragmatics: The semantics of human interaction. Berlin: Mouton de Gruyter.

Zare, H. \& Rajaeepur, S. (2013). THE TASKS OF SOCIAL WORKERS WORKING WITH CHILDREN OF DIVORCE: A REVIEW, UCT Journal of Management and Accounting Studies, 1(1), 5-10.

Zavershinskaya N.A. (2004). Oppozitsiya "svoego” $i$ “chuzhogo” v sovremennoi culture// Vestnik Novgorodskogo gos.universiteta, 41-47.

Zusman V.G. (2001). Svoe i chuzhoe kak koncept culturologii/ Mezhculturnaya communicatsiya. - Nizhniy Novgorod, 242-243. 